\title{
Single-Duct Constant Air Volume System Supply Air Temperature Reset: Using Return Air Temperature or Outside Air Temperature?
}

\author{
Guanghua Wei, P.E. \\ Assistant Research Engineer
}

\author{
W. Dan Turner, Ph.D., P.E. \\ Professor and Director \\ Energy Systems Lab \\ Texas A\&M University \\ College Station, TX 77843 \\ Mingsheng Liu, Ph.D., P.E. \\ Associate Professor \\ Architectural Engineering Program \\ University of Nebraska - Lincoln \\ Omaha, NE 68182
}

\author{
David E. Claridge, Ph.D., P.E. \\ Professor
}

\begin{abstract}
The supply air temperature set point for a singleduct constant air volume air handling unit (AHU) system is often reset based on either return air temperature or outside air temperature in order to reduce simultaneous cooling and heating energy consumption. Both reset strategies make engineering sense as long as the reset schedules are reasonable. Quite often the decision to use one over the other is made with the assumption that they will all achieve some sorts of energy savings. However, the impact of these two strategies on AHU energy consumption could be very different. A comparison of these two commonly used supply air temperature reset strategies for a single-duct constant air volume system is presented in this paper. It is shown that from either the building energy consumption or building comfort point of view, the reset strategy based on outside air temperature is inherently better than that based on return air temperature. Significant amount of heating energy savings can be achieved by switching from return air temperature based reset to outside air temperature based reset. The reset strategy can also benefit variable air volume (VAV) AHUs. An improved supply air temperature set point reset control strategy is proposed by combining and staging the outside air and return air temperature based resets.
\end{abstract}

\section{INTRODUCTION}

In order to reduce simultaneous cooling and heating energy consumption, the supply air temperature set point for a single-duct constant air volume AHU is often reset based on system load conditions. Variables such as return air temperature and outdoor air temperature are frequently used as indications of load conditions. The supply air temperature set point is thus reset based on either return air temperature or outside air temperature. As the return air temperature or outside air temperature increases, the AHU supply air temperature set point decreases to meet the increased cooling load.

Although typical single-duct VAV systems are often designed for constant supply air temperature set point, they are also good candidates for supply air temperature reset, especially when the total supply air flow approaches the minimum setting and the heating energy savings outweigh the fan power penalties. Significant amount of energy savings are achievable through supply air temperature reset for VAV systems (Norford et al 1986).

Zone requirements are direct indications of system load conditions and they are also used for supply air temperature reset. Normally, the supply air temperature set point is set at the highest value that will keep the zone requiring the most cooling at its set points and zone humidity within acceptable limits (Mutammara and Hittle 1990, ASHRAE 1999). The drawback of this reset scheme is that it can potentially have one or two hot spots dictating the supply air temperature set point. This scheme can be seen as one variation of return air temperature based reset.

The energy savings implications of choosing one reset scheme over another can be very different in real systems due to the impacts from control system characteristics, load patterns, and occupant interventions. This paper focuses on the comparison and evaluation of return air temperature based and outside air temperature based supply air temperature reset strategies. 


\section{RESET BASED ON RETURN AIR TEMPERATURE}

This is a popular supply air temperature reset scheme. And the control logic is fairly easy to set up. In some direct digital control (DDC) systems, this reset scheme has become a built-in function. A typical reset schedule for a constant volume singleduct reheat system is shown in Figure 1. The supply air temperature set point is reset between $55^{\circ} \mathrm{F}$ and $62^{\circ} \mathrm{F}$, depending on the return air temperature. If the return air temperature is equal to or higher than $75^{\circ} \mathrm{F}$, the supply air temperature is set at $55^{\circ} \mathrm{F}$. As the return air temperature decreases, the supply air temperature set point increases linearly. The set point reaches $62^{\circ} \mathrm{F}$ when the return air temperature is equal to or below $68^{\circ} \mathrm{F}$. This control schedule is a classical proportional control concept, which allows return air temperature to vary from $68^{\circ} \mathrm{F}$ to $75^{\circ} \mathrm{F}$. This method can result in significant comfort complaint while the system is working strictly based on design intents.

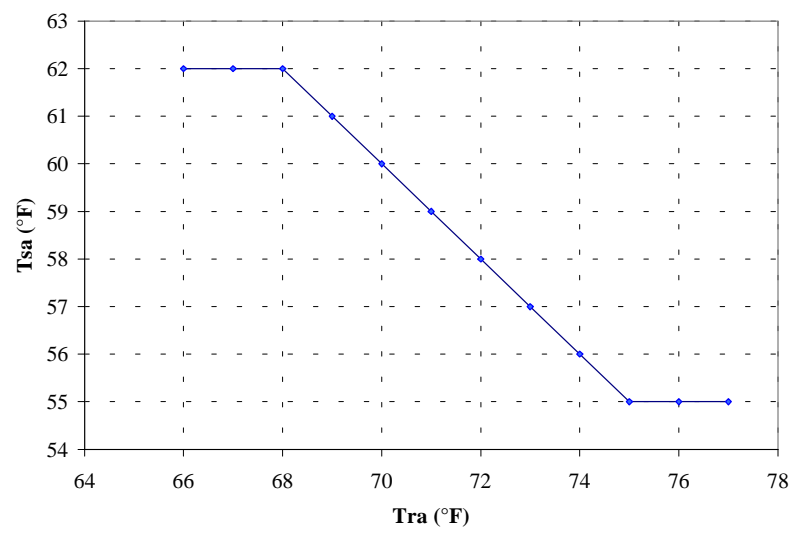

Figure 1. Typical Supply Air Temperature Reset Schedule Based On Return Air Temperature

\section{How Does It Work}

Figure 2 shows the time series plot of discharge air temperature (DAT) for a single-duct constant air volume AHU with terminal reheat. The unit serves the post-surgery patient recovery area in a hospital located in Minneapolis, Minnesota. Exterior floor area accounts for approximately half of the total space area. Room temperatures are controlled by pneumatic thermostats. The AHU has a minimum outside air damper and a maximum outside air damper. The minimum outside air damper is fully open when the AHU is in operation. The maximum outside air damper is modulated to maintain supply air temperature during economizer mode. Also shown in the chart are the outside air temperature and the position of the maximum outside air damper (Note that the maximum outside air damper position varies from $-25 \%$ to $125 \%$, with $-25 \%$ meaning fully open and $125 \%$ meaning fully close).

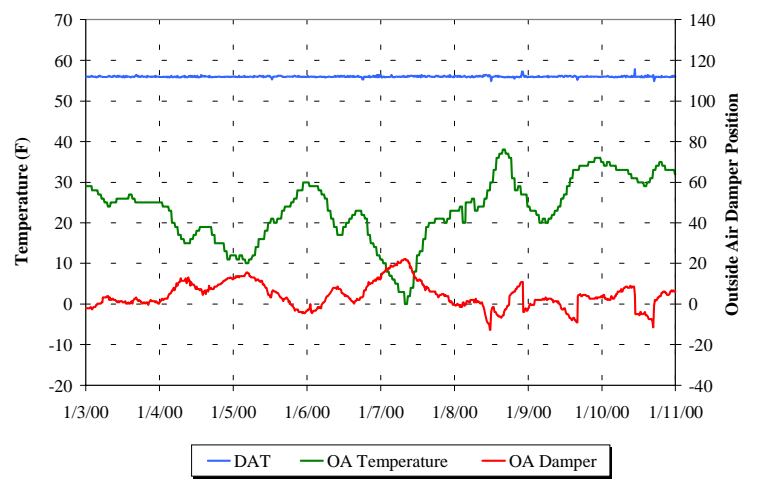

Figure 2. Supply Air Temperature of A Single-Duct Constant Air Volume AHU

The supply air temperature set point is reset based on the return air temperature. For every degree of return air temperature lower than $75^{\circ} \mathrm{F}$, the supply air temperature is reset $0.83^{\circ} \mathrm{F}$ higher than $56^{\circ} \mathrm{F}$. The chart shows that by modulating the maximum outside air damper, the supply air temperature has been maintained at around $56^{\circ} \mathrm{F}$ for the entire period. With outside air temperature ranging from $0^{\circ} \mathrm{F}$ to $38^{\circ} \mathrm{F}$, and dehumidification no longer a concern, one may wonder why didn't the supply air temperature be reset higher than $56^{\circ} \mathrm{F}$ ? What's wrong with this reset schedule?

To better understand how this reset scheme responds to building load change, thus resulting in supply air temperature reset, it is helpful to explain the role of thermostat. In the following section, we explain the way how the thermostat works, the type of thermostat, and the relationship between room temperature set point and return air temperature.

\section{The Role Of Thermostat}

Traditional pneumatic thermostat is a proportional $(\mathrm{P})$ type controller. It senses the space temperature changes and produces an output signal that is proportional to the deviation of space temperature from the set point. The output signal is sent to modulate terminal devices such as hot water reheat control valve to maintain space temperature.

The throttling range (TR) is the total change in the controlled variable (space temperature) that is required to cause the controlled device (reheat control valve) to move between its limits. For example, if the 
space temperature set point is $73^{\circ} \mathrm{F}$ and the thermostat throttling range is $4^{\circ} \mathrm{F}$, then the reheat control valve travels from fully open to fully close between a space temperature of $71^{\circ} \mathrm{F}$ and $75^{\circ} \mathrm{F}$. Figure 3 shows the characteristics of this controller.

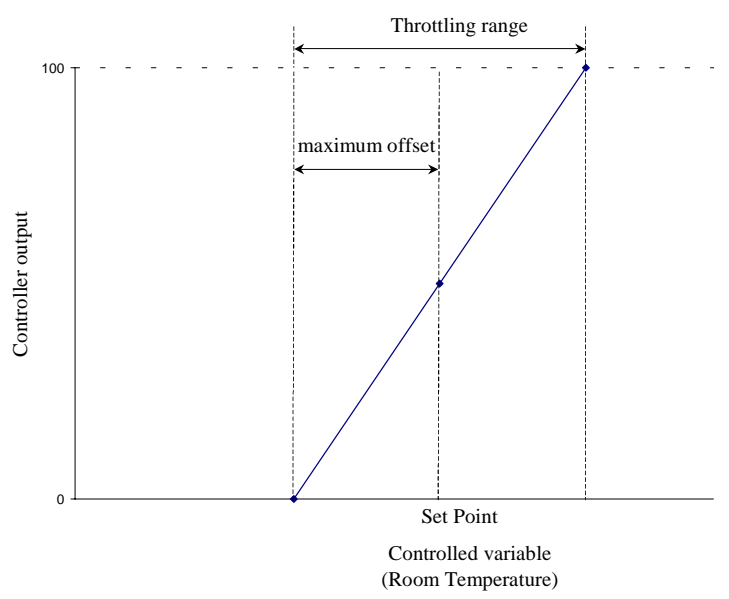

Figure 3. The Characteristics of Proportional Only Controller

Proportional only controllers are characterized by a steady-state offset. From Figure 3, it can be seen that the offset is smaller if the throttling range is smaller. However, there is a limit to which one can reduce the throttling range to reduce the offset, because small throttling range can result in unstable control. In fact, this type of offset actually results in energy saving since it naturally increase room cooling temperature set point and reduce heating temperature set point (Benton 1982).

With DDC system, the function of the thermostat is replaced by a digital space temperature sensor and control software. The DDC system not only can perform the proportional only control, but also the integral control. The primary reason for integral control is to eliminate steady-state offsets. The combination of these two controls is proportional plus integral (PI) control, a widely used control strategy for common HVAC control applications.

Now, let's take a closer look at the reset schedule shown in Figure 1. If the space temperatures are controlled by pneumatic thermostats, the room temperature will be lower than the thermostat set point during heating season. Consequently, the return air temperature will be cooler too, allowing the reset schedule to raise the supply air temperature set point during the heating season. However, the underlying assumption here is that the thermostat settings remain the same throughout the year. Our field experience suggests that this is hardly the case. Very often, the thermostat settings are raised by the occupants in the heating season to higher set points. If the reheat system is capable of delivering the necessary reheat, the return air temperature is likely to be higher than that in the cooling season. Thus, the supply air temperature set point may not be reset at all. The AHU is still delivering $56^{\circ} \mathrm{F}$ air while it may be able to satisfy the cooling load with $62^{\circ} \mathrm{F}$ supply air temperature! Assuming that the cooling is free through economizer operation, this still represents a huge heating energy penalty.

If the space temperatures are controlled by DDC system, the result may be a little different, depending on the configuration of space temperature controller. If the space temperature controller is set up as $\mathrm{P}$ only control, and there are push buttons in the space for the occupant to adjust the temperature set points, then the response of the return air temperature to load changes is similar to the case where pneumatic thermostats are used. If the space temperature controller is set up as PI control, then the space temperature could be maintain at the set point during heating season without any offset, provided that the system has enough reheat capacity. Thus, the return air temperature may not change at all. Hence, no reset will occur for the supply air temperature set point.

For P only space temperature controller with constant set points, it is possible to reduce the reset range for return air temperature, so that the supply air temperature reset schedule is more sensitive to return air temperature changes. However, there is a limit to it. If the reset range is too small, the supply air temperature set point may be reset too high during low cooling load conditions, and may complicate the space relative humidity control.

Fortunately, the solution to this problem is readily available. In the following section, we compare the return air based and outside air based reset schemes. A new control strategy that combines these two reset schemes is also introduced.

\section{RESET BASED ON OUTSIDE AIR TEMPERATURE}

For a return air temperature based reset, the supply air temperature set point will not change unless the return air temperature changes, regardless of the ambient conditions - that is, whether or not it is in cooling season or in heating season. We call this a "passive" reset scheme.

Unlike return air temperature based reset, the outside air temperature based reset approach is a "proactive" reset scheme. The assumption is that the system cooling load varies as a function of the outside air temperature. The simplest function is a 
linear relationship between building cooling load and outside air temperature. The optimal reset schedule can be developed using more sophisticated methods based on load pattern and the humidity control requirement. A typical supply air temperature reset schedule based on outside air temperature is shown in Figure 4. The supply air temperature is reset between $55^{\circ} \mathrm{F}$ and $62^{\circ} \mathrm{F}$, depending on the outside air temperature. If the outside air temperature is equal to or higher than $60^{\circ} \mathrm{F}$, the supply air temperature is set at $55^{\circ} \mathrm{F}$. As the outside air temperature decreases, the supply air temperature set point increases linearly. The set point reaches $62^{\circ} \mathrm{F}$ when the outside air temperature is equal to or below $30^{\circ} \mathrm{F}$. Note that in this case, the supply air temperature set point does not wait for the return air temperature to change. The schedule resets the supply air temperature higher when the ambient air temperature drops in anticipating that the system cooling load will decreases.

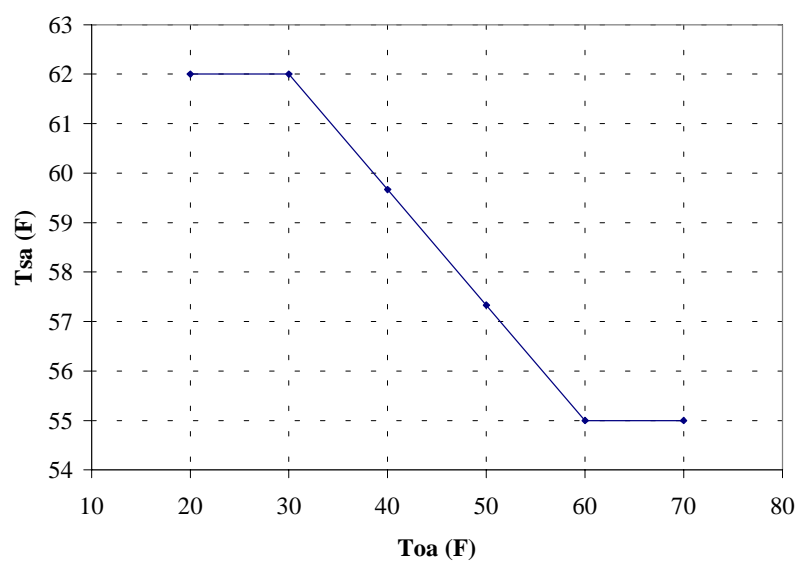

Figure 4. Typical Supply Air Temperature Reset Schedule Based On Outside Air Temperature

Since the outside air temperature based reset schedule is usually developed based on the engineer's experience and the characteristics of the space load the AHU serves, the first cut schedule is far from optimal. It is possible, however, to refine the reset schedule by combining these two reset schedules. The supply air temperature is first reset between $55^{\circ} \mathrm{F}$ and $62^{\circ} \mathrm{F}$ based on outside air temperature, as shown in Figure 4. Then, the return air temperature is used to correct the reset schedule, as shown in Figure 5. The amount of offsets added to the reset schedule depends on the return air temperature. For example, if the return air temperature is equal to or below $70^{\circ} \mathrm{F}$, the supply air temperature set point will be increased by $3^{\circ} \mathrm{F}$, regardless of the outside air temperature. On the other hand, if the return air temperature is equal to or greater than $76^{\circ} \mathrm{F}$, the supply air temperature set point will be decreased by $1^{\circ} \mathrm{F}$. The two reset schedules compliment each other and can produce a quite robust reset schedule that can meet the space cooling needs with improved heating

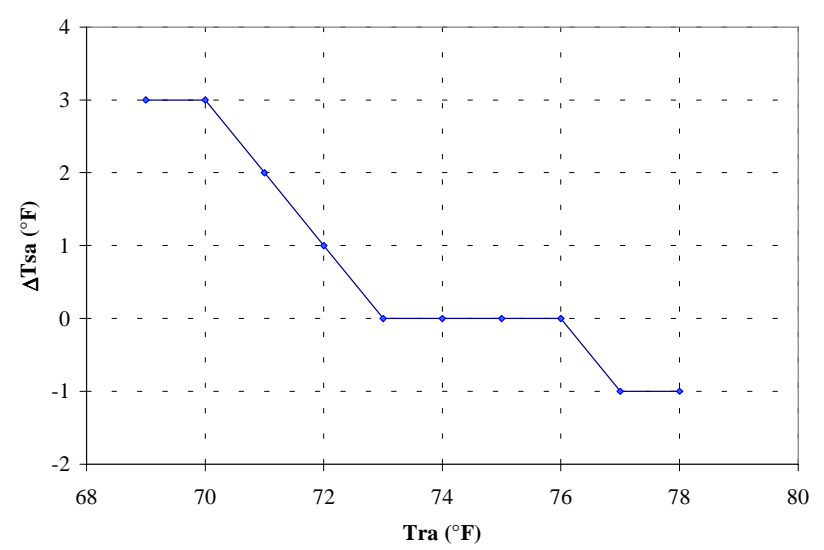

energy consumption.

Figure 5. Corrections on Supply Air Temperature Reset Schedule using Return Air Temperature

\section{CASE STUDY}

In this section, we present one case study where outside air temperature based reset for supply air temperature set point is implemented in the control system as part of a Continuous Commissioning ${ }^{\text {SM }}$ $\left(\mathrm{CC}^{\mathrm{SM}}\right)$ effort.

The building involved in this case study is an out-patient hospital building located in Minneapolis, Minnesota. Two single-duct constant air volume AHUs serve this 40,000 $\mathrm{ft}^{2}$ building. Total supply air flow was 63,000 CFM and outside air flow was 18,310 CFM. The supply air temperature for both AHUs were kept at $55^{\circ} \mathrm{F}$ all year round. Both AHUs had economizer cycle. Major CC activities included:

1. Reducing the total supply air flow rate by adjusting the supply fan motor sheave size

Total supply air flow was reduced from 63,000 CFM to 41,580 CFM.

2. Reducing outside air flow rate to ASHRAE recommended levels (ASHRAE 62-1999 Ventilation for Acceptable Indoor Air Quality)

Minimum outside air intake was reduced from 18,310 CFM to 11,640 CFM.

3. Resetting the supply air temperature set point based on outside air temperature 
The supply air temperature was reset between $55^{\circ} \mathrm{F}$ and $65^{\circ} \mathrm{F}$, with corresponding outside air temperature of $85^{\circ} \mathrm{F}$ to $40^{\circ} \mathrm{F}$.

Figure 6 is a comparison of the measured whole building reheat hot water consumption before and after the Continuous Commissioning effort. Simulation result indicated that approximately $19 \%$ of total reheat energy savings shown in Figure 6 is derived from supply air temperature reset.

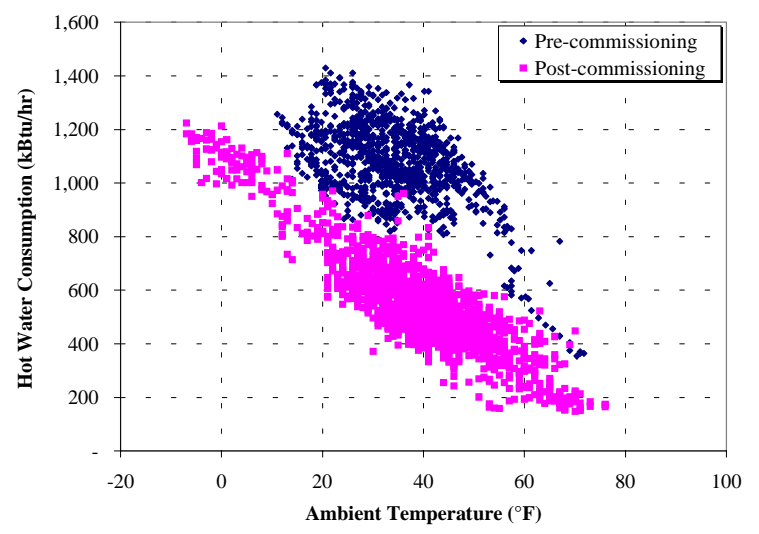

Figure 6. Comparison of Heating Energy Consumption Before and After CC

\section{RESULTS AND DISCUSSION}

This paper compares two widely used supply air temperature set point reset strategies for a single-duct constant air volume AHU system - return air temperature based and outside air temperature based reset schemes. It is shown that the actual supply air temperature for a return air temperature based reset strategy not only depends on the type of room temperature controllers, but also building occupant interventions. On the other hand, it is shown that the reset strategy based on outside air temperature is inherently better than that based on return air temperature. The case study demonstrated that reset the supply air temperature set point based on outside air temperature could result in significant amount of heating energy savings, which may not be materialized at all if the reset schedule was based on return air temperature. By combining and staging the outside air and return air temperature based resets, one can develop an improved reset strategy that can save energy as well as ensuring building thermal comfort.

\section{ACKNOWLEDGEMENTS}

The authors would like to thank Dean Thompson, Gary Schoenhals, Mike Partlow, John
Marshall, and other operating personnel at FairviewUniversity Medical Center for their great support and cooperation during the process of Continuous Commissioning. Special thanks goes to Mark Hancock at Center for Energy and Environment for his effort in helping measure the hot water consumption data.

\section{REFERENCES}

Benton, R. "The impact of thermostat performance on energy consumption and occupant comfort in residential electric heating systems". ASHRAE Trans. 1982, vol.88, Part.1, pp. 1029-1041.

Chen, X. and Kamimura, K. "Vote method of deciding supply air temperature setpoint for VAV airconditioning system". ASHRAE Trans., 2001, vol.107, part 1, pp. 82-92.

Mutammara, A. W. and Hittle, D. C. "Energy effects of various control strategies for variable air volume systems". ASHRAE Trans. 1990, vol.96, part 1, pp. 98-102.

Norford, L. K., Rabl, A., and Socolow, R. H. "Control of supply air temperature and outdoor air flow and its effect on energy use in a variable air volume system". ASHRAE Trans., 1986, vol. 92, Part 2B, pp. 30-45.

ASHRAE Applications Handbook, 1999, pp. 40.23. 